\title{
Orthopaedic outpatients' assessment of information, continuity and care: An intervention study
}

\author{
Birgitte Nørgaard $^{1,3}$, Poul-Erik Kofoed ${ }^{2,}$, J ette Ammentorp ${ }^{3,4}$ \\ 1. Emergency Department, Kolding Hospital, a part of Lillebaelt Hospital, Denmark. 2. Department of Paediatrics, Kolding \\ Hospital, a part of Lillebaelt Hospital, Denmark. 3. Institute of Regional Health Services Research, University of Southern \\ Denmark, Denmark. 4. Health Services Research Unit, Lillebaelt Hospital, Denmark
}

Correspondence: Birgitte Nørgaard. Address: Emergency Department, Kolding Hospital, Skovvangen 2-8, DK - 6000 Kolding, Denmark. Email: birgitte.noergaard@rsyd.dk.

Received: February 3, 2013

DOI : $10.5430 /$ jnep.v4n1p42
Accepted: April 1, 2013

URL: http://dx.doi.org/10.5430/jnep.v4n1p42

\section{Abstract}

Introduction: Despite the increasing interest in patient-centered communication in health care, patient surveys continue to show that patients experience serious problems connected with poor communication. Research has provided evidence that health care professionals' communication skills and patient-centredness can be enhanced through training. The aim of this study was to investigate whether a communication skills training course for health care professionals would improve the adult orthopaedic out-patient's experience of quality of information, care and continuity.

Methods: An intervention study assessing the effect of a communication skills training course for health care professionals on the orthopaedic outpatients' evaluation of the quality of care. Data were collected using a computer touch screen questionnaire with 19 items rated on a four-point scale assessing patients' evaluation of information, continuity and care. Patients were included consecutively in the study (non-equivalent groups).

Results: A total of 11.631 patients answered the questionnaire; 8.315 before and 3.316 after the intervention. The proportion of patients giving top ratings after the course increased for 6 of 19 questions, of which three showed significant increases ( $p<0.05$ ). For 13 of 19 questions the test showed decreasing rates of top scores with seven significant results ( $p$ $>0.05)$.

Discussion: The results were ambiguous as to the impact of the course on the outpatients' assessment. Among the trends found, are a more positive impact on nurses' communication as compared to doctors' communication and a positive impact on patients' assessment of care in general.

\section{Key words}

Communication, Communication skills training, Patients’ assessment

\section{Introduction}

Over the last decades, communication in health care has moved away from a predominantly paternalistic approach characterised by one-way information with the doctor as the decision-maker ${ }^{[1]}$ into an interactional partnership model where doctors and patients share the decision-making ${ }^{[2,3]}$. Despite the fact that patient-centred communication has provided a focus area in health care, patient surveys continue to show that patients experience serious problems connected 
with poor communication. The need for more training in patient-centred communication is underscored by research demonstrating that doctors tend to underestimate patients' level of distress and that they tend to feel complacent about their own performance ${ }^{[4]}$. Among the main communicational problems reported by patients, we find a lack of information or incorrect information, a lack of readiness to meet patients' needs and expectations and a lack of respect and involvement ${ }^{[5]}$. A partnership approach requires certain communication skills from the health care professionals such as the ability to cope with shared decision-making processes, attentive listening and patient-centred communication ${ }^{[2]}$. Research has provided ample evidence that health care professionals' communication skills and patient-centeredness can be enhanced through training ${ }^{[6-16]}$, for example by increasing doctors' empathy and problem-defining skills ${ }^{[16]}$ or their tendency to elicit information about patients' concerns ${ }^{[17]}$. Furthermore, it has been shown that patient centred communication and shared decision making is appreciated by patients and they give high priority to doctors' information being comprehensible ${ }^{[18]}$ and a positive association between medical ICU nurses' assessment of nurse-doctor communication and collaboration and patient outcomes (e.g. severity of illness, death and readmission rates) has been established ${ }^{[19]}$. Ineffective communication has also been shown to be a common causal factor underlying many adverse events and medical errors ${ }^{[20]}$, and delays in patient care ${ }^{[21]}$. However, only few studies have been able to show that training can improve the outcomes of the patients ${ }^{[5]}$ and more research in patient-centred communication has been requested. The aim of this study was to investigate whether a communication skills training course for health care professionals would improve the adult orthopaedic out-patient's experience of quality of information, care and continuity.

\section{Methods}

An intervention study was carried out in an orthopaedic out-patient clinic in a general hospital in Denmark from 2007 to 2010 assessing the effect of a communication skills training course for health care professionals on the patients' evaluation of quality of care. Data were collected using a touch screen questionnaire. Responses from the period before the intervention were compared with responses after the intervention. All health care professionals in the department, i.e. doctors, nurses, nursing assistants, medical secretaries, service staff and managers, attended the training course.

\subsection{Sample}

During the period 1st May 2007 to 30th April 2010 patients aged 18 years and above examined in the outpatient clinic were included in the study consecutively (non-equivalent groups) if they could speak and read Danish. Patients assessed by the nurses not to be able to answer a questionnaire on a touch screen were ineligible and the reasons for ineligibility were registered, e.g. cognitive limitations, wheelchair users, poor eyesight or severe immobilisation. The before measuring period lasted 16 months, the after measuring period 13 months and the training period 7 months (a total of 36 months).

\subsection{I ntervention}

The intervention was a communication course offered to all health care professionals in the department. The specific goal of the training was to enhance the participants' communication skills in terms of accuracy, efficiency and supportiveness by giving them some simple yet useful communication principles that were immediately applicable to their daily work in the department ${ }^{[22]}$. The course was based on the Calgary-Cambridge Observation Guide, which provided a structure for an effective patient interview ${ }^{[23]}$. The structure includes shared agenda, taking both the patients' and the health care professionals' needs into account, and communication principles, such as attentive listening, the use of silence and summarizing ${ }^{[22,23]}$. The training method was based on the British psychiatrist Peter Maguire's work on medical communication, which is a skill-based approach making use of videotaped scenarios, role-plays and simulated communication sequences ${ }^{[24]}$. These teaching strategies were incorporated into the training course.

The training course comprised 24 hours spread over three days. On the first day the elements of an effective interview were presented (initiating the session; gathering information; explanation and planning; closing the session) and role plays were 
used to provide practice applying the principles. On the second day the training focused on role plays addressing psychological reactions from patients, passing on bad news, problematic discussions with colleagues, and communication with relatives. Six weeks later, a third day of training was offered. The six-week interval gave the participants opportunity to practice their new communication principles. At the end of the second day the participants should choose a specific topic to practice: a communication principle (e.g. pausing, empathy, hints) or a part of the structure (e.g. initiating or closing the session). Participants were encouraged to choose a topic that was relevant to them. In the six-week interval they were asked to videotape an authentic communication situation with a patient or a colleague. Before the follow-up day all participants were expected to review their recording with a colleague in order to check for both the interview structure and use of the communication principles with a specific focus on the topic chosen by the individuals.

The recordings provided the focus for plenary discussions, supervision and personal feedback sessions during the followup session at the third day. A few professionals came to the follow-up day without a video recording. In these cases, the professionals were transferred to another follow-up day and given the needed support and supervision so that they could make a video recording and contribute to the plenary discussions.

The training sessions were conducted by eight in-house trainers (each session was led by two trainers) who were recruited to represent each profession (two doctors, one medical secretary and five nurses). The trainers received forty hours of training from a certified trainer on communication with patients and colleagues in an extended version of the training course over a period of five days. Afterwards, they received an additional five days of training in teaching and supervising their colleagues. Of the 181 staff members who completed the training course 21 were doctors, 102 nurses, 30 nursing assistants, 17 secretaries and 11 were other staff members, including service staff and managers.

\subsection{The questionnaire}

The questionnaire for the patients was based on the Interpersonal Skills (IPS) rating form developed and validated by Schnabl et al. ${ }^{[25]}$. The questionnaire was translated from English to Danish in a two-stage process and pilot tested in an earlier study carried out in a department of paediatrics on 12 parents ${ }^{[26]}$ and afterwards adjusted and used in an additional study including 2832 parents in a pediatric department ${ }^{[27]}$ and 3.133 orthopaedic in-patients showing a Cronbach's Alpha of 0.88 with all questions collapsed ${ }^{[28]}$.

The questionnaire contained 19 items categorised as: information (12 items), continuity (3 items) and care (4 items). The answers were rated on a four-point scale from "To a considerable extent" to "Not at all” with the possibility of responding "Not relevant". All questions are shown in Table 2. The respondents were asked to give separate ratings for the communicative performance of doctors and nurses who conducted the consultations.

The questionnaires were filled in on a fixed touch screen placed in the ward. Access to the touch screen was gained using a bar code scanner card supplied by the nurses.

\subsection{Statistics}

Data were entered directly from the touch screen into the Multi Lingual Survey System (MLSS) and then transferred into Stata, version 12 for analysis (StataCorp. 2001. Statistical Software: Release 12. College Station, TX: Stata Corporation).

Data on patients' assessment of the quality of information, continuity and care were dichotomized into two groups: the top rating (5 points) versus the collapsed results of the four lower ratings. Data were then sorted according to the time periods: before the training course (P1) and after the training course (P2). Data were described by proportions and analysed by linear regression tests. A power of $80 \%$ (0.80) and 5\% significance level was chosen. 


\subsection{Ethical considerations}

The patients were informed regarding the aim of the study, their right to remain anonymous and to withdraw at any time without consequences for their actual or future care and treatment. This information was given orally by nurses when the bar code scanner card for the touch screen questionnaire was handed out and in writing on the first page of the questionnaire. All personal identifiers were removed or disguised from all data to preclude personal identification. The study was licensed by the Danish Data Protection Agency and needed no further ethical approval according to Danish legislation. The study was approved by the Head of Department.

\section{Results}

\subsection{Population}

During the data collection periods (P1 and P2) a total of 60.066 patients were examined in the outpatient clinic of which 22.495 were excluded due to former mentioned ineligibility criteria, leaving a total of 37.571 included patients. A total of 14.378 patients answered the questionnaire in the project period. The answers given when the training course took place (2.747) were excluded leaving 11.631 responses for analysis. In P1 8.315 responses were obtained from 23.941 included patients (response rate: 34.7 \%) and in P2 3.316 responses were obtained from 13.630 included patients (response rate: 24.3 \%). The responders' mean ages were 39.7 in P1 (SD: 20.2; median: 41) and 42.3 in P2 (SD: 18.8; median: 43). With regard to gender distribution, no difference was found between the two periods. The responders' mean age and gender distributions are shown in Table 1.

Table 1. Responders by gender and mean age

\begin{tabular}{|c|c|c|c|c|c|c|c|c|}
\hline \multirow[b]{3}{*}{ P1-before training course } & \multicolumn{8}{|c|}{ Gender } \\
\hline & \multicolumn{4}{|c|}{ N (\%) } & \multicolumn{4}{|c|}{ Mean age } \\
\hline & $3402(41 \%)$ & $4433(53 \%)$ & $480(6 \%)$ & 8315 & 39.8 & 39.0 & 45.7 & 39.7 \\
\hline P2-after training course & $1318(40 \%)$ & $1874(56 \%)$ & $124(4 \%)$ & 3316 & 42.1 & 42.2 & 50.8 & 42.3 \\
\hline
\end{tabular}

\subsection{Patients' assessment of information, continuity and care}

Linear regressions tests showed increases in the number of patients giving the top ratings for 6/19 questions, of those three questions with significant increases $(p<0.05)$ after the training course. For 13/19 questions the test showed decreases in the number of patients giving top ratings after the training course with seven significant results $(p>0.05)$. In Table 2 the proportion of patients giving top ratings, their OR's, CIs and p-values are shown for each question.

Three of the six questions with a significant increase involved the nurses' communication, whereas the corresponding questions involving doctors' communication have a decreased (one significant and two non-significant) proportion of patients giving top ratings after the training course. The remaining three questions with an increased proportion of patients giving top ratings concerned care (e.g. kindness, obligingness, involvement). With respect to the questions with a significant decrease, 4/7 questions involved communication with doctors, and the remaining three questions with a significant decrease represented continuity (coherent information). This means that after the training course the number of patients given top ratings to the three questions about continuity decreased, whereas the number increased for three out of four questions about care (two significantly and one non-significantly) after the training course. Three of twelve (3/12) questions about information had an increased (1 significant) and the remaining 9/12 a decreased (four significant) amount of top ratings after the training course. 
Table 2. Patients' evaluation of information, care and continuity, by proportion of patients. ORs for top ratings ("To a considerable extent") before (P1) and after (P2) training course

\begin{tabular}{|c|c|c|c|c|c|c|}
\hline Information & $\begin{array}{l}\text { P1 (\%) } \\
(n=8315)\end{array}$ & $\begin{array}{l}\text { P2 (\%) } \\
(n=3316)\end{array}$ & $\begin{array}{l}\text { Difference } \\
\text { P1-P2 (\%) }\end{array}$ & OR & $95 \%$ CI & $p$ \\
\hline $\begin{array}{l}\text { Do you experience that the doctor has been } \\
\text { prepared for your interviews? }\end{array}$ & 73.2 & 71.0 & -2.2 & 0.90 & 0.83-0.99 & 0.026 \\
\hline $\begin{array}{l}\text { Do you experience that the nurses have been } \\
\text { prepared for your interviews? }\end{array}$ & 69.9 & 70.1 & 0.2 & 1.01 & $0.91-1.13$ & 0.829 \\
\hline $\begin{array}{l}\text { Did the doctor use a language you could } \\
\text { understand? }\end{array}$ & 84.8 & 84.5 & -0.3 & 0.98 & $0.88-1.10$ & 0.740 \\
\hline $\begin{array}{l}\text { Did the nurses use a language you could } \\
\text { understand? }\end{array}$ & 87.3 & 89.3 & 2.0 & 1.18 & $1.01-1.37$ & 0.033 \\
\hline $\begin{array}{l}\text { Have you been given the opportunity to explain } \\
\text { your problem/illness to the doctor? }\end{array}$ & 82.7 & 80.2 & -2.5 & 0.85 & $0.77-0.94$ & 0.002 \\
\hline $\begin{array}{l}\text { Have you been given the opportunity to explain } \\
\text { your problem/illness to the nurses? }\end{array}$ & 70.2 & 69.2 & -1.0 & 0.94 & 0.84-1.05 & 0.280 \\
\hline $\begin{array}{l}\text { Did the doctor explain to you about } \\
\text { examinations and treatments? }\end{array}$ & 80.3 & 77.6 & -2.7 & 0.87 & 0.79-0.96 & 0.006 \\
\hline $\begin{array}{l}\text { Did the nurses explain to you about } \\
\text { examinations and treatments? }\end{array}$ & 67.0 & 65.2 & -1.8 & 0.91 & $0.81-1.02$ & 0.117 \\
\hline Did the doctor explain to you about future plans? & 81.1 & 77.9 & -3.2 & 0.85 & $0.77-0.94$ & 0.002 \\
\hline Did the nurses explain to you about future plans? & 64.8 & 66.0 & 1.2 & 1.04 & $0.92-1.16$ & 0.550 \\
\hline $\begin{array}{l}\text { Are you satisfied with the information you } \\
\text { received from the doctor? }\end{array}$ & 83.5 & 80.7 & -2.8 & 0.85 & $0.76-0.94$ & 0.002 \\
\hline $\begin{array}{l}\text { Are you satisfied with the information you } \\
\text { received from the nurses? }\end{array}$ & 79.5 & 78.8 & -0.7 & 0.95 & $0.83-1.08$ & 0.441 \\
\hline \multicolumn{7}{|l|}{ Care } \\
\hline Did you experience kindness and obligingness? & 90.2 & 91.3 & 1.1 & 1.16 & $1.01-1.33$ & 0.035 \\
\hline Did the doctor have enough time for you? & 82.2 & 83.1 & 0.9 & 1.08 & $0.97-1.20$ & 0.172 \\
\hline Did the nurses have enough time for you? & 80.0 & 82.0 & 2.0 & 1.17 & $1.02-1.34$ & 0.023 \\
\hline $\begin{array}{l}\text { Have you been involved in your care and } \\
\text { treatment? }\end{array}$ & 74.9 & 73.2 & -1.7 & 0.93 & $0.84-1.03$ & 0.178 \\
\hline \multicolumn{7}{|l|}{ Continuity } \\
\hline $\begin{array}{l}\text { Were the information you received from the } \\
\text { doctors coherent? }\end{array}$ & 65.6 & 62.0 & -3.6 & 0.87 & $0.80-0.95$ & 0.001 \\
\hline $\begin{array}{l}\text { Were the information you received from the } \\
\text { nurses coherent? }\end{array}$ & 63.7 & 60.3 & -3.4 & 0.88 & 0.78-0.98 & 0.002 \\
\hline $\begin{array}{l}\text { Were the overall information you received } \\
\text { coherent? }\end{array}$ & 67.1 & 64.5 & -2.6 & 0.91 & 0.83-0.99 & 0.028 \\
\hline
\end{tabular}

\section{Discussion}

The aim of this study was to investigate whether a communication skills training course for health care professionals would improve the adult orthopaedic out-patient's experience of quality of information, care and continuity. The overall lack of a positive impact on patients' assessment of especially information and continuity in this study is remarkable, as a study at the same department assessing in-patients evaluation of information, continuity and care showed a significantly increased satisfaction for 15/19 questions after exactly the same communication skills training course ${ }^{[28]}$. Nevertheless, the tendency in the outpatients' assessment towards a negative impact of the training on especially the doctors' communication could be compared to the findings in the in-patient study in which a non-significant increase was found for 3 of the 
19 items, all 3 concerned doctors' communication ${ }^{[28]}$. The training course was implemented in a real-word setting with many competing demands and met with varying levels of commitment, and an explorative interview study revealed that especially the doctors were opponent towards the training course ${ }^{[29]}$. The doctors' resistance showed to be primarily caused by the mandatory status of the course and by the interprofessional course design. In the interviews, the doctors also stated that the training course had given them nothing new or useful, but on the contrary had been disturbing for them ${ }^{\text {[29] }}$. The outpatients' assessment of the doctors' communication might support these findings - or be a consequence of the negative attitude towards the concept of the training.

On the other hand, the field is abound in research results showing a training effect on self-efficacy ${ }^{[7,8,10,30,31]}$, but sparse on results showing more satisfied patients after a communication skills training course for health care professionals. In fact, more studies are unsuccessful in showing significant impact of communication training on patients' satisfa-

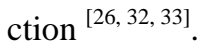

The fact that a lower baseline results in higher relative increases has been pointed out by Riiskjær et al. ${ }^{[34]}$, which could be of relevance for this study. Most of the items (16/19) in the questionnaire are doublets assessing either doctors' or nurses' communication regarding a specific focus, e.g. using an understandable language, being prepared for the interview or explaining about future plans (i.e. eight profession specific items). For seven of these profession specific items, the questions about the nurses' communication were rated lowest at baseline and, in all eight items; they had the highest increase or the lowest decrease (highest delta) after the training course. A relatively large group was excluded from the survey (53\%), as the patients had difficulties participating. The fact that the questionnaire was electronic made it not appealing to elderly people; it was located on a platform not accessible for wheel chair users, a light reflection on the screen made it difficult to read for people with sight impairments. The low response rate could be a weakness of the study. However, as the results from before the intervention were compared to the results after, it is of interest whether the rates of satisfaction changed under the condition that the patient populations were comparable. The differences in gender and age were small and could hardly explain the differences in the degree of satisfaction. Furthermore, reviewing the literature, the influence on patient satisfaction by non-participation is not clear. While some argue that non-responders cause biased results ${ }^{[35,36]}$, others maintain that non-responders never have been proved to be less satisfied than responders ${ }^{[37]}$ or to differ markedly on socio-demographical parameters ${ }^{[38-40]}$. In this study the responders did not differ noticeably from the overall group of patients scheduled to the out-patient clinic during the project period in neither gender distribution nor mean age. A comparable study of inpatients assessment of communication showed age to be a confounder with ORs between 1.000243 and 1.008992 per year for the top rating, but repeated analysis with adjustment for age resulted in only minor changes (in OR), with no effect on the conclusions ${ }^{[28]}$. Regression analysis did not detect similar confounders in this study.

Both the low response rate and the result reflect the difficulties in doing implementation research. In a busy outpatient ward it is difficult to maintain a high response rate. Furthermore, as the study was an effectiveness study carried out in a department in full work study conditions are controllable only to a certain extent and other events occurred, which could influence both the patient satisfaction directly and the priorities of the health staff, making it less likely that the influence of a communication skills training could be detected. While this could be considered to be a weakness of the study design, it also reflects real day-to-day conditions in health care. Furthermore, as pointed out the baseline patient satisfaction was rather high making it difficult to detect an improvement.

\section{Conclusion}

Whereas this study showed an ambiguous impact of the communication skills training course for health care professionals on orthopaedic outpatients' assessment of information, care and continuity, some trends are apparent. They include a more consistently positive impact on the nurses' communication as compared to the doctors' communication. Likewise, patients' assessment of the care provided by both doctors and nurses saw significant gains. The results indicate a need for 
further investigation of both communication skills training methods for health care professionals and the applicability of communication methods and tools in clinical practice. Furthermore, it points out the difficulties in performing research on the impact caused by the implementation of new strategies in health care.

\section{Sources of support}

We gratefully acknowledge the generous support of Lillebaelt Hospital, the Department of Orthopaedic Surgery, Kolding Hospital, the Research Foundation of Fredericia and Kolding Hospitals, the Memorial Foundation of Gudrun Krause and the Danish Nurses’ Organization.

\section{Reference}

[1] Berry D. Health Communication. Theory and Practice. Berkshire, England: Open University Press; 2007.

[2] Charles C, Whelan T, Gafni A. What do we mean by partnership in making decisions about treatment? BMJ. 2007 ; 319: 780-2. http://dx.doi.org/10.1136/bmj.319.7212.780

[3] Donabedian A. Quality assurance in health care: consumers' role (The Lichfield Lecture). Quality in Health Care. 1992; 1(4): 247-51. PMid:10136873 http://dx.doi.org/10.1136/qshc.1.4.247

[4] Ford S, Fallowfield L, Lewis S. Can oncologists detect distress in their out-patients and how satisfied are they with their own performance during bad news consultations? Br J Cancer. 1994; 70: 767-70. PMid:7917937

http://dx.doi.org/10.1038/bjc.1994.393

[5] Ammentorp J, Mainz J, Sabroe S. Communication in health care - with a focus on adult patients' and children/adolescents' perspectives of quality. Ugeskr laeger. 2006; 168(40): 3437-42. PMid:17032612

[6] Bredin M, Corner J, Krishnasamy M, Plant H, Bailey C, A'Hern R. Multicentre randomised controlled trial of nursing intervention for breathlessness in patients with lung cancer. BMJ. 1999; 318. 3 April. http://dx.doi.org/10.1136/bmj.318.7188.901

[7] Ammentorp J. The impact of a training course on the communication skills of medical doctors and nurses. A randomized controlled trial. PhD thesis. Faculty of Health Sciences University of Aarhus; 2007.

[8] Fallowfield LJ. How to Improve the Communication Skills of Oncologist. Annals of Oncology. 2000; 11(3): 63-8 (6).

[9] Fellowes d, Wilkinson S, Moore P. Communication skills training for health care professionals working with cancer patients, their families and/or cares. Cochrane Database of Systematic Reviews. 2004. http://dx.doi.org/10.1002/14651858.CD003751.pub2(3).

[10] Finset A, Ekeberg O, Eide H, Aspegren K. Long term benefits of communication skills training for cancer doctors. Psychooncology. 2003 Oct; 12(7): 686-93. PMid:14502593 http://dx.doi.org/10.1002/pon.691

[11] Langewitz WA, Eich P, Kiss A, Wössmer B. Improving Communication Skills - A Randomized Controlled Behaviorally Oriented Intervention Study for Residents in Internal Medicine. Psychosomatic Medicine. 1998; 60: 268-76. PMid:9625213

[12] Maguire P, Fairbairn S, Fletcher C. Consultation skills of young doctors: I-Benefits of feedback training in interviewing as students persist. Br Med J. 1986; 14(292(6535)): 1573-6. http://dx.doi.org/10.1136/bmj.292.6535.1573

[13] Parle M, Maguire P, Heaven C. The development of a training model to improve health professionals' skills, self-efficacy and outcome expectancies when communicating with cancer patients. Soc Sci Med. 1997; 44(2): 231-40. http://dx.doi.org/10.1016/S0277-9536(96)00148-7

[14] Razavi D, Delvaux N, Marchal S, Bredart A, Farvacques C, Paesmans M. The Effects of a 24-h Psychological Training Program on Attitudes, Communication Skills and Occupational Stress in Oncology: a randomised study. Eur J Cancer. 1993; 29A (13): 1858-63. http://dx.doi.org/10.1016/0959-8049(93)90538-Q

[15] Van Dulmen AM, Holl RA. Effects of continuing paediatric education in interpersonal communication skills. Eur J Pediatr. 2000; 159: 489-95. PMid:10923220 http://dx.doi.org/10.1007/s004310051316

[16] Roter D, Hall JA, Kern DE, Barker R, Cole KA, Roca RP. Improving Physicians' Interviewing Skills and Reducing Patients' Emotional Distress. Arch Intern Med. 1995; 155(17): 1877-84. PMid:7677554 http://dx.doi.org/10.1001/archinte.1995.00430170071009

[17] Joos SK, Hickam DH, Gordon GH, Baker LH. Effects of a Physician Communication Intervention on Patient Care Outcomes. Journal of general internal medicine. 1996; 11(3): 147-55-187-8.

[18] Robinson FP, Gorman G, Slimmer LW, Yudkowsky R. Perceptions of Effective and Ineffective Nurse-Physician Communication in Hospitals. Nursing Forum. 2010; 45(3): 206-16. PMid:20690996 http://dx.doi.org/10.1111/j.1744-6198.2010.00182.x 
[19] Baggs JG, Schmitt MH, Mushlin AI, Eldredge DH, Hutson AD. Association between nurse-physician collaboration and patient outcomes in three intensive care units. Crit Care Med. 1999; 27(9): 1991-8. PMid:10507630 http://dx.doi.org/10.1097/00003246-199909000-00045

[20] Reader TW, Flin R, Cuthbertson BH. Communication skills and error in the intensive care unit. Current Opinion in Critical Care. 2007; 13: 732-6. PMid:17975399 http://dx.doi.org/10.1097/MCC.0b013e3282f1bb0e

[21] Reed RG, Silverman R, Schwind C, Fortune JB, Sutyak J, Horvath KD, et al. Surgeon Information Transfer and Communication. Factors Affecting Quality and Efficiency of Inpatient Care. Annals of Surgery. 2007; 245(2): 159-69. PMid:17245166 http://dx.doi.org/10.1097/01.sla.0000242709.28760.56

[22] Silverman J, Kurtz S, Draper J. Skills for Communicating with Patients. Second ed. Oxford: Radcliffe Publishing; 2005.

[23] Kurtz SM, Silverman JD. The Calgary-Cambridge Referenced Observation Guides: an aid to defining the curriculum and organizing the teaching in communication training programmes. Med Educ. 1996; 30(2): 83-9. PMid:8736242 http://dx.doi.org/10.1111/j.1365-2923.1996.tb00724.x

[24] Maguire P, Pitceathly C. Key communication skills and how to acquire them. BMJ. 2002; 325: 697-700. PMid:12351365 http://dx.doi.org/10.1136/bmj.325.7366.697

[25] Schnabl GK, Hassard TH, Kopelow ML. Extending the skills measured with standardized patient examinations. The Assessment of Interpersonal Skills Using Standardized Patients. Academic Medicine. 1991 Sep; 66(9): 34-6. http://dx.doi.org/10.1097/00001888-199109000-00033

[26] Ammentorp J, Sabroe S, Kofoed PE, Mainz J. Effects of a communication course for clinicians on parents' perception of care - a randomized controlled trial. Scand J Caring Sci. 2009; 23(3): 506-17. PMid:19291083 http://dx.doi.org/10.1111/j.1471-6712.2008.00653.x

[27] Ammentorp J, Kofoed PE, Laulund LW. Impact of communication skills training on parents' perception of care: intervention study. J Adv Nurs. 2011; 67(2): 394-400. PMid:20955186 http://dx.doi.org/10.1111/j.1365-2648.2010.05475.x

[28] Nørgaard B, Kofoed PE, Kyvik KO, Ammentorp J. Communication skills training for health care professionals improves the adult orthopaedic patient's experience of quality of care. Scandinavian Journal of Caring Sciences 12 A.D. Mar 16.

[29] Nørgaard B, Ammentorp J, Kyvik KO, Kofoed PE. Health care professionals' experience of participating in a communication course in an orthopaedic department. International Journal of Orthopaedic and Trauma Nursing. 2011 Nov 1; 15 : $202-11$. http://dx.doi.org/10.1016/j.ijotn.2011.06.001

[30] Ammentorp J, Kofoed PE. Coach training can improve the self-efficacy of neonatal nurses. A pilot study. Patient Educ Couns. 2009. http://dx.doi.org/10.1016/j.pec.2009.08.015

[31] Ammentorp J, Sabroe S, Kofoed PE, Mainz J. The effect of training in communication skills on medical doctors' and nurses' selfefficacy. A randomized controlled trial. Patient Educ Couns. 2007; 66(3): 270-7. PMid:17337337 http://dx.doi.org/10.1016/j.pec.2006.12.012

[32] Shilling V, Jenkins V, Fallowfield L. Factors Affecting Patient and Clinician Satisfaction with the Clinical Consultation: Can Communication Skills Training for Clinicians Improve Satisfaction? Psycho-Onchology. 2008; 12: 599-611. PMid:12923800 http://dx.doi.org/10.1002/pon.731

[33] Jensen BF, Gulbrandsen P, Dahl FA, Krupat E, Frankel RM, Finset E. Effectiveness of a short course in clinical communication skills for hospital doctors: Results of a crossover randomized controlled trial (ISRCTN22153332). Patient Education and Counseling. 2011; 84: 163-9. PMid:21050695 http://dx.doi.org/10.1016/j.pec.2010.08.028

[34] Riiskjær E, Ammentorp J, Nielsen JF, Kofoed PE. Patient surveys - A key to organizational change? Patient Educ Couns. 2009; http://dx.doi.org/10.1016/j.pec.2009.08.017.

[35] Rubin H. Can Patients Evaluate the Quality of Hospital Care? Med care Res Rev. 1990; 47: 267. http://dx.doi.org/10.1177/107755879004700302

[36] Asch D, Jedrziewski MK, Christakis NA. Response Rates to mail Surveys Published in Medical Journals. J Clin Epidemiol. 1997; 50(10): 1129-36. http://dx.doi.org/10.1016/S0895-4356(97)00126-1

[37] Lasek R, Barkley W, Harper D, Rosenthal G. An Evaluation on the Impact of Nonresponse Bias on Patient Satisfaction Surveys. Medical Care. 1997; 35(6): 646-52. PMid:9191708 http://dx.doi.org/10.1097/00005650-199706000-00009

[38] Etter JF, Perneger TV. Analysis of Non-Response Bias in a Mailed Health survey. J Clin Epidemiol. 1997; 50(10): 1123-8. http://dx.doi.org/10.1016/S0895-4356(97)00166-2

[39] Parker CJ, Dewey ME. Assessing research outcomes by postal questionnaire with telephone follow-up. International Journal of Epidemiology. 2000; 29: 1065-9. PMid:11101549 http://dx.doi.org/10.1093/ije/29.6.1065

[40] Vestbo J, Rasmussen FV. Baseline characteristics are not sufficient indicators of non-response bias in follow up studies. Journal of Epidemiology and Community Health. 1992; 46: 617-9. PMid:1494079 http://dx.doi.org/10.1136/jech.46.6.617 